\title{
KELAYAKAN BAHAN AJAR FISIKA BERBASIS INKUIRI TERBIMBING UNTUK MELATIHKAN KETERAMPILAN PROSES SAINS PESERTA DIDIK
}

\author{
Iqrima Rahmawati ${ }^{1}$., Mastuang ${ }^{2}$., Suyidno ${ }^{3}$., Titin Sunarti ${ }^{4}$ \\ ${ }^{1}$ Prodi Pendidikan Fisika FKIP Universitas Lambung Mangkurat, Banjarmasin, Indonesia \\ e-mail: iiqrimarahma@gmail.com \\ ${ }^{2}$ Prodi Pendidikan Fisika FKIP Universitas Lambung Mangkurat, Banjarmasin, Indonesia \\ e-mail: mastuang_pfis@ulm.ac.id \\ ${ }^{3}$ Prodi Pendidikan Fisika FKIP Universitas Lambung Mangkurat, Banjarmasin, Indonesia \\ e-mail: suyidno_pfis@ulm.ac.id \\ ${ }^{4}$ Jurusan Fisika FMIPA Universitas Negeri Surabaya, Surabaya, Indonesia \\ e-mail: titinsunarti@unesa.ac.id
}

Submit: 08-06-2020 Revisi: 27-06-2020 Diterima: 08-07-2020 Diterbitkan: 17-08-2020

\begin{abstract}
Abstrak: Keterampilan proses dan aktivitas sains termasuk keterampilan dasar dalam belajar fisika, namun kurang dilatihkan di sekolah. Oleh karena itu, penelitian ini bertujuan untuk menghasilkan bahan ajar fisika berbasis inkuiri terbimbing yang layak untuk melatihkan keterampilan proses peserta didik. Penelitian pengembangan ini menggunakan desain model ADDIE. Uji coba dilakukan pada 23 peserta didik di kelas XI IPA 1 SMAN 12 Banjarmasin. Data dikumpulkan melalui instrumen validasi bahan ajar, pengamatan keterlaksanaan RPP dan aktivitas sains, serta tes hasil belajar. Teknik analisis data dilakukan secara deskriptif kualitatif dan n-gain. Hasil penelitian menunjukkan bahwa; (1) setiap komponen RPP, LKPD, materi ajar, dan THB dalam kriteria valid, (2) setiap komponen RPP dapat dilaksanakan dengan baik, (3) aktivitas sains peserta didik dalam kriteria sangat baik, dan (4) keterampilan proses dan hasil belajar peserta didik meningkat dalam kriteria sedang. Dengan demikian, bahan ajar fisika berbasis inkuiri terbimbing termasuk layak untuk melatih keterampilan proses sains peserta didik.
\end{abstract}

Kata kunci: Bahan Ajar Fisika, Inkuiri Terbimbing, Keterampilan Proses Sains

\section{THE FEASIBILITY OF PHYSICS TEACHING MATERIALS BASED GUIDED INQUIRY TO TRAIN STUDENTS' SCIENCE PROCESS SKILLS}

\begin{abstract}
Process skills and science activities include basic skills in learning physics, but lack of training in school. Therefore, this research aims to produce physics teaching materials based on guided inquiry that is feasible to train students' science process skills. This development used Dick \& Carry design model. The subject of trial was 23 students of XI IPA 1 at SMAN 12 Banjarmasin. Data obtained through the instrument of expert validation, lesson plan observation, science activity observation, and learning outcomes test. The data analysis was done by descriptively qualitatively and n-gain. The study results showed; (1) the components of lesson plan, worksheet, learning material, and learning outcomes test are valid criteria, (2) the implementation of the lesson plan in good criteria, and (3) students' science activity is very good criteria, and (4) students' science process skill and learning outcomes increase in medium criteria. Thus, physics teaching materials based on guided inquiry is feasible for enhancing students' science process skills.
\end{abstract}

Keywords: Physics Teaching Material, Guided Inquiry, Science Process Skills 
Rahmawati, Mastuang, Suyidno, \& Sunarti. (2020). Kelayakan Bahan Ajar Fisika Berbasis Inkuiri Terbimbing untuk Melatihkan Keterampilan Proses Sains Peserta Didik

\section{PENDAHULUAN}

Di era abad 21, Pemerintah Republik Indonesia menetapkan bahwa capaian kompetensi lulusan jenjang pendidikan dasar dan menengah diutamakan melalui pembelajaran yang berpusat pada peserta didik dan menekankan pendekatan saintifik dalam menggali dan menemukan ilmu pengetahuan (Kemendikbud, 2016b). Pendekatan saintifik atau keterampilan proses mendasari setiap pembelajaran di sekolah, termasuk dalam pembelajaran fisika (Prayitno dkk., 2017). Pembelajaran fisika dapat menggunakan metode ilmiah yang merujuk pada teknik-teknik investigasi ilmiah atas fenomena atau gejala, memperoleh pengetahuan baru, atau mengoreksi dan memadukan ilmu pengetahuan yang sebelumnya (Mustika, dkk., 2016). Berbagai keterampilan yang mendasari pembelajaran fisika agar peserta didik lebih mandiri dalam menggali dan menemukan pengetahuan sendiri adalah Keterampilan Proses Sains (KPS). KPS adalah kemampuan peserta didik dalam melakukan tahapan-tahapan metode secara ilmiah untuk memperoleh pengetahuan (Rinarta dkk., 2014). KPS merupakan keterampilan dasar yang harus dimiliki peserta didik dalam mempelajari fisika (Prayitno dkk., 2017). Oleh karena itu, KPS termasuk penting untuk dilatihkan ke peserta didik karena diperlukan dalam membangun pemahaman terhadap pengetahuan, memudahkan belajar melalui praktikum langsung dan pengumpulan informasi agar peserta didik menjadi lebih mandiri. Dalam belajar fisika, KPS dapat digunakan dalam merumuskan hipotesis, mengidentifikasi variabel, mencoba, menganalisis dan menyimpulkan hasil percobaannya (Rohmah dkk., 2017).

Kenyataannya, keterampilan proses selama ini masih menjadi permasalahan dalam pembelajaran fisika. Pembelajaran fisika masih ditekankan hafalan konsep-konsep tanpa melibatkan peserta didik secara langsung dalam proses mencari, memahami, dan mengembangkan konsepnya dalam kehidupan nyata (Ayuningtyas dkk., 2015; Azizah dkk., 2014; Metaputri dkk., 2016; Sudiarman, Soegimin, \& Susantini, 2015). Hal ini diperkuat hasil studi awal peneliti bahwa penguasaan KPS peserta didik kelas XI IPA 1 di SMAN 12 Banjarmasin masih dalam kriteria kurang baik. Hal ini dikarenakan bahan ajar yang digunakan di sekolah kurang memadai dan model pembelajaran yang diterapkan kurang melatihkan KPS, di mana penggunaan RPP diperoleh dari MGMP, hanya tersedia buku teks fisika, dan belum ada LKPD berbasis KPS. Bahan ajar tersebut harusnya disesuaikan dengan karakteristik peserta didik agar KPS dapat dilatihkan dengan baik. Bahan ajar sendiri adalah bentuk bahan yang digunakan untuk memudahkan guru dalam merencanakan dan melaksanakan proses pembelajaran (Daryanto \& Dwicahyono, 2014). Bahan ajar didesain berdasarkan tujuan pembelajaran, karakteristik peserta didik dan materi ajar, serta strategi pembelajaran (Suparman, 2012). Kelayakan suatu bahan ajar ditinjau dari tiga aspek yaitu validitas, kepraktisan, dan keefektifan. Validitas menentukan kualitas bahan ajar yang dikembangkan (Plomp, 2013). Valid tidaknya bahan ajar tergantung dari pertimbangan para pakar atau validator, di mana para validator diminta menilai bahan ajar yang dikembangkan dan memberikan masukan perbaikan agar bahan ajar yang dikembangkan lebih baik (Akbar, 2017). Kepraktisan mengandung pengertian bahwa suatu alat ukur berupa instrumen dapat dilaksanakan dengan mudah, di mana kepraktisan dapat dilihat dari keterlaksanaannya dalam pembelajaran di kelas (Putri dkk., 2014). Selain itu, bahan ajar dikatakan efektif ketika tujuan instruksional khusus yang direncanakan telah tercapai (Akbar, 2017; Putri dkk., 2014).

Pembelajaran bermakna memerlukan bahan ajar berkualitas yang bisa membantu peserta didik memahami dan menguasai materi fisika dengan baik (Ayuningtyas dkk., 2015). Oleh karena itu, pengembangan bahan ajar perlu mempertimbangkan karakteristik peserta didik dan materi yang akan diajarkan, serta memilih suatu model pembelajaran yang tepat untuk melatihkan KPS (Latifah dkk, 2017). Model pembelajaran yang dirasakan tepat untuk digunakan dalam pengembangan bahan ajar adalah model inkuiri terbimbing. Dalam inkuiri terbimbing, peserta didik mendapatkan sedikit latihan dalam merancang penyelidikan sendiri dan menuntut peserta didik untuk merumuskan prosedur sendiri (Ayuningtyas dkk., 2015; Azizah dkk., 2014; Metaputri dkk., 2016; Diani dkk., 2016). Penerapan inkuiri terbimbing dalam pembelajaran fisika memberikan peluang kepada peserta didik untuk mencari informasi dan membuat penjelasan langsung di bawah bimbingan guru, serta peserta didik dibekali kemampuan menyelesaikan masalah melalui KPS (Prasojo, 2016). Kelebihan model inkuiri terbimbing di antaranya memberikan ruang kepada peserta didik untuk belajar sesuai dengan gaya belajarnya sendiri, sedangkan kelemahannya adalah model ini memerlukan perubahan kebiasaan cara belajar peserta didik yang sebelumnya berpusat pada guru (Shoimin, 2014). Beberapa teori belajar yang melandasi inkuiri terbimbing adalah teori perkembangan kognitif Piaget bahwa pengalaman belajar yang langsung melibatkan aktivitas peserta didik dalam belajar mampu meningkatkan perkem- 
bangan kognitifnya, serta teori Bruner bahwa mereka belajar melalui keterlibatan aktif dan bereksperimen untuk memperoleh pengalaman dan menemukan prinsip-prinsip (Suyidno dkk., 2020).

Berdasarkan permasalahan di atas, tujuan penelitian ini adalah menghasilkan bahan ajar fisika berbasis inkuiri terbimbing yang layak untuk melatihkan keterampilan proses sains peserta didik. Bahan ajar ini diharapkan memudahkan peserta didik dalam beraktivitas sains maupun inkuiri ilmiah layaknya seorang ilmuan dalam mencari dan menemukan ilmu pengetahuan.

\section{METODE PENELITIAN}

Penelitian ini termasuk penelitian pengembangan dengan model ADDIE. Pada tahap analysis-design, telah dihasilkan spesifikasi bahan ajar fisika berbasis inkuiri terbimbing pada materi elastisitas dan hukum Hooke. Pada tahap developt, dikembangkan draf bahan ajar dan dilanjutkan uji validasi oleh tiga pakar pembelajaran fisika. Setelah dinyatakan valid oleh ketiga pakar, dilakukan simulasi terbatas untuk mengetahui kepraktisan bahan ajar secara harapan. Selanjutnya, tahap implementation, dilakukan uji coba kelas sebenarnya untuk mengukur kepraktisan dan keefektifan bahan ajar. Uji coba menggunakan one group pretest posttest design pada 23 peserta didik kelas XI IPA 1 SMAN 12 Banjarmasin tahun ajaran 2018/2019. Peserta didik pada awalnya diminta mengerjakan pre-test hasil belajar, kemudian diterapkan bahan ajar fisika berbasis inkuiri terbimbing selama tiga pertemuan. Selama proses pembelajaran, dua observer mengamati aktivitas guru dan mencatat dalam instrumen pengamatan keterlaksanaan RPP, serta tiga observer mengamati aktivitas sains peserta didik dan mencatatnya dalam instrumen pengamatan aktivitas sains. Pada akhir pertemuan, peserta didik diminta kembali untuk mengerjakan post-test hasil belajar. Sementara, tahap evaluation dilakukan untuk merevisi draf pada setiap tahapan dan sebagai bahan untuk memfinalisasi bahan ajar fisika tersebut.

Teknik analisis data validitas bahan ajar, keterlaksanaan RPP, dan aktivitas sains peserta didik dilakukan secara deskriptif kualitatif, yaitu rerata skor yang diperoleh dalam skala 1-4 disesuaikan dengan kriteria; sangat baik (skor $>3,33)$, baik $(3,00 \geq$ skor $>2,00)$, cukup $(2,00 \geq$ skor $>0,67)$, kurang (skor $\geq 0,67$ ) (Adaptasi Umaeza \& Widodo, 2017), yang kemudian dideskripsikan secara logis. Adapun data pre-test dan post-test keterampilan proses dan hasil belajar dianalisis dengan persamaan $n$ gain (Hake, 1999) dan hasilnya disesuaikan dengan kriteria; tinggi $(g \geq 0,7)$, sedang $(0,7>g \geq 0,3)$, dan rendah $(g<0,3)$.

\section{HASIL DAN PEMBAHASAN}

Penelitian ini berusaha menghasilkan bahan ajar fisika (RPP, LKPD, materi ajar, THB) berkualitas sebagaimana ditetapkan oleh Plomp (2013), yaitu suatu bahan ajar dikatakan berkualitas tinggi ketika memenuhi kriteria validitas, kepraktisan, dan keefektifan. Hasil penelitian akan diuraikan di bawah ini.

\section{Validitas Bahan Ajar Fisika Berbasis Inkuiri Terbimbing}

Validitas bahan ajar menggambarkan kualitas bahan ajar yang ditinjau dari penilaian pakar berkaitan dengan aspek kebutuhan, kemutakhiran, dan konsistensi dari bahan ajar yang dikembangkan. Hasil validasi bahan ajar disajikan pada Tabel 1 .

Tabel 1. Validitas bahan ajar

\begin{tabular}{llcccc}
\hline \multirow{2}{*}{ Bahan Ajar } & \multirow{2}{*}{ Aspek Penilaian } & \multicolumn{2}{c}{ Validitas } & \multicolumn{2}{c}{ Reliabilitas } \\
\cline { 3 - 6 } & & Rerata Skor & Kriteria & $\boldsymbol{\alpha}$ & Kriteria \\
\hline RPP & Perumusan tujuan & 3,80 & Sangat baik & 0,81 & Tinggi \\
& Bahasa & 3,56 & Sangat baik & & \\
& Isi RPP & 3,56 & Sangat baik & & \\
\hline Waktu & 3.83 & Sangat baik & & \\
\hline \multirow{2}{*}{ MKPD } & Format LKPD & 3,43 & Sangat baik & 0,84 & Tinggi \\
& Bahasa & 3,17 & Baik & & \\
& Isi LKPD & 3,78 & Sangat baik & & Tinggi \\
& Isi materi ajar & 3,44 & Sangat baik & 0,93 & \\
& Penyajian & 3,36 & Baik & & \\
& Bahasa & 3,36 & Baik & & \\
& Kegrafikan & 3,21 & Baik & & \\
\hline
\end{tabular}


Rahmawati, Mastuang, Suyidno, \& Sunarti. (2020). Kelayakan Bahan Ajar Fisika Berbasis Inkuiri Terbimbing untuk Melatihkan Keterampilan Proses Sains Peserta Didik

\begin{tabular}{|c|c|c|c|c|c|}
\hline THB & $\begin{array}{l}\text { Soal } 1 \\
\text { Soal } 2 \\
\text { Soal } 3 \\
\text { Soal } 4 \\
\text { Soal } 5 \\
\text { Soal } 6 \\
\text { Soal } 7 \\
\text { Soal } 8 \\
\text { Soal } 9\end{array}$ & $\begin{array}{l}3,51 \\
3,48 \\
3,51 \\
3,48 \\
3,51 \\
3,48 \\
3,51 \\
3,48 \\
3,48\end{array}$ & $\begin{array}{l}\text { Sangat baik } \\
\text { Sangat baik } \\
\text { Sangat baik } \\
\text { Sangat baik } \\
\text { Sangat baik } \\
\text { Sangat baik } \\
\text { Sangat baik } \\
\text { Sangat baik } \\
\text { Sangat baik }\end{array}$ & 0,76 & Tinggi \\
\hline
\end{tabular}

Tabel 1 menunjukkan semua komponen bahan ajar fisika termasuk dalam kriteria valid. Hal ini berarti RPP, materi ajar, LKS, dan THB yang dikembangkan memenuhi standar proses pada jenjang pendidikan menengah pada Kurikulum 2013 revisi 2017. RPP dibuat untuk tiga kali pertemuan pada materi elastisitas dan hukum Hooke pada kelas XI, rincian kegiatan pembelajaran berdasarkan sintaks dari model inkuiri terbimbinng. Pertemuan 1 dan 3 berdurasi 3 x 45 menit (3 JP) dan pertemuan berdurasi 2 x 45 menit (2 JP). RPP dirancang sesuai standar proses (Kemendikbud, 2016b), terdiri atas identitas sekolah, identitas mata pelajaran, kelas atau semester, materi pokok, alokasi waktu, tujuan pembelajaran, kompetensi dasar, dan indikator capaian kompetensi, materi pembelajaran, metode pembelajaran, media pembelajaran, sumber belajar, langkah pembelajaran (pendahuluan, inti, dan penutup), dan penilaian hasil pembelajaran.

LKPD sebagai sarana peserta didik untuk mencari informasi dan permasalahan yang akan dicari kebenarannya sesuai dengan tujuan percobaan yang dicantumkan pada halaman awal LKPD agar KPS dapat dilatihkan kepada peserta didik. LKPD berisi tugas dan langkah-langkah yang menuntun peserta didik mengelola pola berpikir secara terarah (Arifin dkk., 2015). LKPD mengacu pada model pembelajaran inkuiri terbimbing dan dengan disediakan tempat kosong untuk jawaban peserta didik, alat dan bahan disajikan dalam bentuk gambar, serta langkah-langkah percobaan disediakan untuk memudahkan peserta didik dalam melaksanakan percobaan (Kemendikbud, 2016a). Di LKPD juga disediakan soal pengayaan sebagai latihan untuk pendalaman terhadap materi. LKPD ini dikembangkan sebagai penunjang RPP untuk tiga kali pertemuan. Materi ajar disusun sebagai sumber belajar peserta didik (Ayuningtyas dkk., 2015; Sudiarman dkk., 2015). Isi materi yang terkandung di dalam materi ajar hasil pengembangan ini telah disesuaikan dengan tujuan pembelajaran yang telah dirumuskan sebelumnya. Materi ajar ini memuat judul materi, kata pengantar, daftar isi, standar kompetensi, indikator pencapaian kompetensi, peta konsep, tujuan pembelajaran, uraian materi, contoh soal, latihan, kunci jawaban, rangkuman, glosarium, dan daftar pustaka. Isi materi ajar telah memenuhi aspek materi, kebahasaan, penyajian materi, dan kegrafikan (Sudijono, 2015). Kebaruan materi ajar adalah disediakan gambar dan langkah-langkah percobaan untuk melatihkan KPS, serta disediakan kolom yang berisikan ringkasan konsep fisika yang berkaitan. LKPD dan Materi ajar dinilai baik dan valid karena memenuhi persyaratan konstruksi (bahasa), didaktik (isi LKPD), dan teknis (format LKPD). Selain itu, THB meliputi identitas peserta didik, petunjuk pengerjaan, dan 9 butir soal. Pengembangan butir soal THB dalam bentuk soal uraian dan melibatkan ranah C2 dan C4 yang dilengkapi dengan gambar/tabel data. THB ini termasuk valid karena memenuhi kriteria konstruksi umum dan bahasa. Dengan demikian, bahan ajar fisika yang dikembangkan termasuk valid karena pengembangannya disesuaikan dengan inkuiri terbimbing yang sering digunakan untuk melatihkan keterampilan proses sains.

\section{Kepraktisan Bahan Ajar Fisika Berbasis Inkuiri Terbimbing}

Kepraktisan bahan ajar menggambarkan keterlaksanaan aktivitas pembelajaran dengan memanfaatkan bahan ajar yang dikembangkan, di mana kepraktisannya dapat ditinjau dari keterlaksanaan RPP oleh guru (Putri dkk., 2014) yang disajikan pada Tabel 2.

Tabel 2. Keterlaksanaan RPP

\begin{tabular}{llccc}
\hline \multirow{2}{*}{\multicolumn{1}{c}{ Fase }} & \multicolumn{2}{c}{ Validitas } & \multicolumn{2}{c}{ Reliabilitas } \\
\cline { 2 - 5 } & Rerata Skor & Kriteria & $\alpha$ & Kriteria \\
\hline 1. Mempersiapkan peserta didik & 3,92 & Sangat baik & 0,83 & Tinggi \\
2. Menyajikan permasalahan & 3,75 & Sangat baik & & \\
3. Membimbing merumuskan hipotesis & 3,50 & Sangat baik & \\
4. Membimbing pengumpulan data & 3,75 & Sangat baik & \\
\cline { 2 - 4 } & & \multicolumn{3}{c}{}
\end{tabular}


5. Membimbing penarikan kesimpulan

6. Membimbing refleksi dan proses berpikir

7. Mengingatkan pembelajaran selanjutnya
3,50
3.50
3,67
Sangat baik
Sangat baik
Sangat baik

Berdasarkan Tabel 2, guru mampu memanfaatkan bahan ajar dalam menunjang keberhasilan pembelajaran inkuiri terbimbing. Guru mampu menyiapkan peserta didik dan menyajikan masalah, kemudian membimbing membuat hipotesis, mengumpulkan data, menarik kesimpulan, refleksi situasi masalah dan proses berpikir selama penyelidikan, dan mengingatkan pembelajaran untuk pertemuan selanjutnya. Peserta didik diberi kesempatan untuk mengembangkan rasa keingintahuaannya dan berusaha mencari sendiri jawabannya melalui proses penyelidikan. Model inkuiri terbimbing dapat meningkatkan KPS dan hasil belajar peserta didik (Ayuningtyas dkk., 2015; Azizah dkk., 2014). Pemahaman KPS memudahkan proses penyelidikan sesuai dengan tujuan investigasi (Metaputri dkk., 2016).

\section{Keefektifan Bahan Ajar Fisika Berbasis Inkuiri Terbimbing}

Bahan ajar dikatakan efektif jika tujuan instruksional khusus yang direncanakan telah tercapai (Ayuningtyas dkk., 2015; Sudiarman dkk., 2015). Keefektifan bahan ajar ditentukan berdasarkan aktivitas sains, keterampilan proses sains, dan hasil belajar peserta didik yang disajikan di Tabel 3-4.

Tabel 3. Aktivitas sains peserta didik

\begin{tabular}{lcc}
\hline \multicolumn{1}{c}{ Aspek Pengamatan } & Rerata Skor & Kriteria \\
\hline 1. Merumuskan hipotesis & 4,00 & Sangat baik \\
2. Mengidentifikasi variabel & 3,71 & Sangat baik \\
3. Mencoba/ mengumpulkan data & 3,54 & Sangat baik \\
4. Menganalisis data & 3,47 & Sangat baik \\
5. Membuat kesimpulan & 3,55 & Sangat baik \\
\hline
\end{tabular}

Berdasarkan Tabel 3, penggunaan bahan ajar fisika berbasis inkuiri terbimbing menjadikan aktivitas sains peserta didik dalam kriteria sangat baik. Pembelajaran Inkuiri terbimbing mampu melibatkan aktivitas aktif dan meningkatkan hasil belajar fisika peserta didik (Ayuningtyas dkk., 2015; Azizah dkk., 2014; Subekti \& Ariswan, 2016). KPS berkorelasi signifikan dengan minat belajar peserta didik (Metaputri dkk., 2016). Oleh karena itu, aktivitas inkuiri berdampak konstruktif yang memberi banyak peluang untuk meningkatkan efektivitas pembelajaran $[6,9,30]$. Hal ini diperkuat hasil analisis pre-test dan post-test keterampilan proses sains dan hasil belajar peserta didik menggunakan rumus $n$ gain disajikan pada Tabel 4.

Tabel 4. $N$-Gain keterampilan proses sains dan hasil belajar peserta didik

\begin{tabular}{lcclc}
\hline \multicolumn{1}{c}{ Hasil Belajar } & Skor Pre-test & Skor Post-test & $\boldsymbol{N}$-Gain & Kriteria \\
\hline Keterampilan proses sains & 0,28 & 66,32 & 0,66 & Sedang \\
Kognitif (produk) & 7,51 & 70,72 & 0,68 & Sedang \\
\hline
\end{tabular}

Berdasarkan Tabel 4, penggunaan bahan ajar berbasis inkuiri terbimbing mampu meningkatkan keterampilan proses sains dan hasil belajar peserta didik. Hal ini sesuai hasil penelitian sebelumnya (Ayuningtyas dkk., 2015; Azizah dkk., 2014; Wahyudi \& Supardi, 2013) bahwa pembelajaran inkuiri terbimbing memfasilitasi pengembangan KPS dan hasil belajar peserta didik. Melalui inkuiri terbimbing, peserta didik diberikan kesempatan belajar dan berlatih mempraktikkan KPS dengan lebih mandiri secara bertahap, tetapi masih ada scaffolding dari guru. Limitasi penelitian adalah masih diujicobakan pada satu kelas, sehingga masih diperlukan upaya uji coba dalam skala lebih luas untuk mengetahui konsisten bahan ajar berbasis inkuiri terhadap peningkatan KPS. Limitasi penelitian ini adalah proses pembelajaran inkuiri terbimbing untuk melatih KPS memerlukan waktu lebih lama sehingga disarankan KPS diajarkan minimal 5-6 pertemuan terutama bagi peserta didik yang bekal awal KPS nya masih rendah. Selain itu, guru senantiasa memotivasi dan melibatkan peran tanggung jawab peserta didik untuk berpartisipasi aktif dalam mendukung kesuksesan investigasi secara ilmiah. Namun demikian, temuan ini konsisten dengan hasil penelitian sebelumnya (Azizah dkk., 2014; Kemendikbud, 2016a) bahwa pembelajaran inkuiri terbimbing termasuk layak untuk melatihkan keterampilan proses sains peserta didik peserta didik. 
Rahmawati, Mastuang, Suyidno, \& Sunarti. (2020). Kelayakan Bahan Ajar Fisika Berbasis Inkuiri Terbimbing untuk Melatihkan Keterampilan Proses Sains Peserta Didik

\section{SIMPULAN}

Penelitian ini telah menghasilkan bahan ajar fisika berbasis inkuiri terbimbing yang layak digunakan untuk meningkatkan keterampilan proses sains peserta didik. Para validator telah sepakat bahwa bahan ajar (RPP, LKPD, materi ajar, THB) yang dikembangkan pada materi elastisitas dan hukum Hooke termasuk valid. Selain itu, hasil uji coba penelitian menunjukkan guru mampu melaksanakan tahapan RPP dengan baik sehingga peserta didik mampu berpartisipasi aktif selama pembelajaran fisika, serta keterampilan proses sains dan hasil belajar peserta didik telah meningkat dalam kriteria sedang. Namun, guru disarankan senantiasa melibatkan peran tanggung jawab peserta didik dalam mendukung kesuksesan belajarnya terutama ketika mengatasi kesulitan-kesulitan selama proses inkuiri.

\section{UCAPAN TERIMA KASIH}

Terima kasih kami sampaikan kepada Prodi Pendidikan Fisika FKIP ULM dan SMAN 12 Banjarmasin yang telah memfasilitasi pelaksanaan penelitian ini.

\section{DAFTAR PUSTAKA}

Abdullah, C., Parris, J., Lie, R., Guzdar, A., \& Tour, E. (2015). Critical Analysis of Primary Literature in a Masters Level Class: Effects on Self Efficacy and Science Process Skills Life Sciences Education 14. San Diego: Universitas of California.

Akbar, S. (2017). Instrumen Perangkat Pembelajaran. Bandung: PT Remaja Rosdakarya.

Arifin, U. F., Hadisaputro, S., \& Susilaningsih, E. (2015). Pengembangan Lembar Kerja Praktikum Siswa Terintegrasi Guided Inquiry untuk Keterampilan Proses Sains. Chemistry in Education, 4(1), 54-60.

Ayuningtyas, P., Soegimin, W. W., \& Supardi, Z. I. (2017). Pengembangan Perangkat Pembelajaran Fisika dengan Model Inkuiri Terbimbing untuk Melatihkan Keterampilan Proses Sains Siswa SMA pada Materi Fluida Statis. Jurnal Penelitian Pendidikan Sains, 4(2), 636-647.

Azizah, N., Indrawati, dan Harijanto, A. (2014). Penerapan Model Inkuiri Terbimbing untuk Meningkatkan Keterampilan Proses Sains dan Hasil Belajar Fisika Peserta Didik Kelas X.C di MAN 2 Jember Tahun Ajaran 2013/2014. Jurnal Pendidikan Fisika, 3(3), 235-241.

Daryanto \& Dwicahyono. (2014). Pengembangan Perangkat Pembelajaran (Silabus, RPP, THB, dan Bahan Ajar). Yogyakarta: Gava Media.

Diani, R., Saregar, A., \& Ifana, A. (2017). Perbandingan Model Pembelajaran Problem Based Learning dan Inkuiri Terbimbing Terhadap Kemampuan Berpikir Kritis Peserta Didik. Jurnal Penelitian Pembelajaran Fisika, 7(2), 147-155.

Latifah, S \& Kusyeni, M. (2017). Efektivitas Strategi REACT (Relating, Experiencing, Applying, Cooperating, Transfering) Terhadap Hasil Belajar dan Keterampilan Proses Sains di SMP N 22 Bandar Lampung. Jurnal Penelitian Pembelajaran Fisika, 8(2), 101-108.

Linawati, L. (2014). Efektifitas Penggunaan Model Pembelajaran Kooperatif Tipe Student Facilitator and Explaining terhadap Hasil Belajar Fisika pada Materi Suhu dan Kalor di SMA Walisongo Semarang Tahun Pelajaran 2012/2013. Skripsi Institut Agama Islam Negeri Walisongo. Tidak Dipublikasikan.

Metaputri, N. K., Margunayasa, I. G., Garminah, N. N., \& Hum, M. (2016). Pengaruh Model Pembelajaran Inkuiri Terbimbing dan Minat Belajar terhadap Keterampilan Proses Sains pada Siswa Kelas IV SD. Mimbar PGSD Undiksha, 4(1),1-10.

Mustika, M., Saptaningrum, E., \& Susilawati, S. (2016). Pengaruh Penggunaan LKS dengan Pendekatan Saintifik pada Materi Objek IPA dan Pengamatannya terhadap Hasil Belajar IPA Kelas VII MTs Negeri 1 Semarang. Jurnal Penelitian Pembelajaran Fisika, 7(1), 63-71.

Nurhidayati, S., Zubaidah, S., \& Indriwati, S. E. (2015). Pengaruh Metode Inkuiri Terbimbing Terhadap Aktivitas dan Hasil Belajar Biologi Siswa. Jurnal Kependidikan, 14(3), 285-294.

Peraturan Menteri Pendidikan dan Kebudayaan Nomor 8 Tahun 2016a tentang Buku yang Digunakan oleh Satuan Pendidikan.

Peraturan Menteri Pendidikan dan Kebudayaan Nomor 22 Tahun 2016b tentang Standar Proses Pendidikan Dasar dan Menengah. 
Plomp, T. J. (2013). Educational design research: An introduction. In Plomp $T J$ and Nieveen $N$ (eds) Educational Design Research, part A: An introduction p 10-51. Retrieved 04/05/2016, from http://downloads.slo.nl/Documenten/educational-design-research-part-a.pdf.

Prasojo. (2016). Pengembangan Perangkat Pembelajaran IPA Berbasis Inkuiri Terbimbing untuk Meningkatkan KPS dan Berpikir Kritis. Jurnal Pendidikan Matematika dan Sains, 4(2), 130141.

Prayitno, B. A., Corebima, D., Susilo, H., Zubaidah, S., \& Ramli, M. (2017). Closing the Science Process Skills Gap between Students with High and Low-Level Academic Achievement. Journal of Baltic Science Education, 16(2), 266-277.

Putri, N. W. S \& Ardana, I. M. (2014). Pengembangan Perangkat Pembelajaran Tandur Berbantuan Geogebra sebagai Upaya Meningkatkan Prestasi dan Aktivitas Belajar Geometri Siswa. Jurnal Pendidikan dan Pembelajaran Matematika Indonesia, 3(1), 1-11.

Rinarta, I. N., Yuanita, L., \& Widodo, W. (2014). Pengembangan Perangkat Pembelajaran Model Inkuiri untuk Melatihkan Keterampilan Proses Sains dan Penguasaan Konsep Siswa SMP. Jurnal Pendidikan Fisika, 2(2), 70-88.

Rohmah, K., Susilawati, S., \& Saptaningrum, E. (2017). Penggunaan Alat Peraga Musschenbroek Bimetal terhadap Keterampilan Proses Sains. Jurnal Penelitian Pembelajaran Fisika, 8(2), 8994.

Shoimin, A. (2014). 68 Model Pembelajaran Inovatif dalam Kurikulum 2013. Yogyakarta: Ar-Ruzz Media.

Subekti, Y \& Ariswan, A. (2016). Pembelajaran Fisika dengan Metode Eksperimen untuk Meningkatkan Hasil Belajar Kognitif dan Keterampilan Proses Sains. Jurnal Inovasi Pendidikan IPA, 2(2), 252-261.

Sudiarman, S., Soegimin, W. W., \& Susantini, E. (2017). Pengembangan Perangkat Pembelajaran Fisika Berbasis Inkuri Terbimbing untuk Melatihkan Keterampilan Proses Sains dan Meningkatkan Hasil Belajar pada Topik Suhu dan Perubahannya. Jurnal Penelitian Pendidikan Sains, 4(2), 658-671.

Sudaryono. (2012). Dasar-dasar Evaluasi Pembelajaran. Yogyakarta: Graha Ilmu.

Sudijono, A. (2015). Pengantar Evaluasi Pendidikan. Jakarta: PT Rajagrafindo Persada.

Suparman, A. (2012). Desain Instruksional Modern. Jakarta: Erlangga.

Umaeza, A \& Widodo, W. (2017). Pengembangan Metode Demonstrasi Menggunakan Lembar kerja Siswa (LKS) Simulasi Online pada Materi Fluida. Jurnal Penelitian Pembelajaran Fisi$k a, 8(2), 95-100$.

Wahyudi, L. E \& Supardi, Z. A. (2013). Penerapan Model Pembelajaran Inkuiri Terbimbing pada Pokok Bahasan Kalor untuk Melatihkan Keterampilan Proses Sains terhadap Hasil Belajar di SMAN 1 Sumenep. Inovasi Pendidikan Fisika, 2(2), 62-65.

Widoyoko, E. P. (2017). Evaluasi Program Pembelajaran. Yogyakarta: Pustaka Pelajar. 
Rahmawati, Mastuang, Suyidno, \& Sunarti. (2020). Kelayakan Bahan Ajar Fisika Berbasis Inkuiri Terbimbing untuk Melatihkan Keterampilan Proses Sains Peserta Didik 